\title{
THE FORMATION OF HABITS AT HIGH SPEED
}

\author{
OTTO C. GLASER
}

From the Zoölogical Laboratory of the University of Michigan

WITH TWO FIGURES

CONTENTS

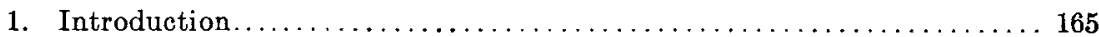

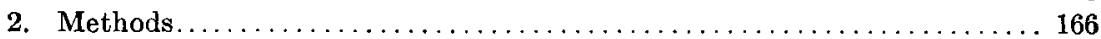

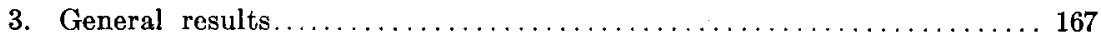

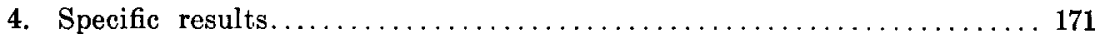

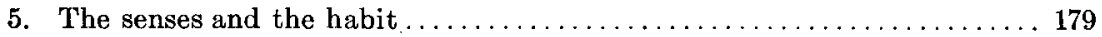

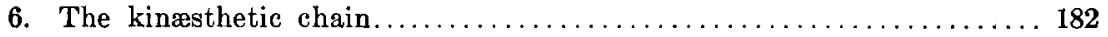

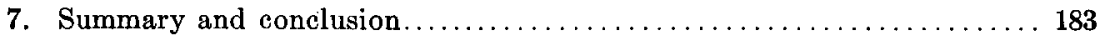

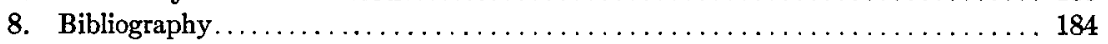

\section{INTRODUCTION}

The method by which habits are ordinarily educed consists essentially in presenting a problem whose solution depends on the slow, and often painful suppression of irrelevant actions, and the survival of only those that count. The results so achieved are invaluable, but from the nature of the case difficult to verify. So much time is required that students of all classes are apt to be told in words, rather than by actual experiments, what has been accomplished in this interesting field. Habits formed slowly and gradually are not only incapable of quick demonstration, but the "slow method" leaves altogether untouched, a wide range of behavior. Animals do not always act slowly; they do not always overcome, with deliberation and care, the difficulties that block

\footnotetext{
1 Directly, as well as indirectly, I am indebted to Miss Frances J. Dunbar, and to Miss Nina Gage, for many of the results on which the present communication is based.
} 
the road to food and comfort; indeed, in nature there are many problems whose solution must be accomplished at once with the utmost rapidity, and to the swift alone is the race.

\section{METHODS}

The animals used were white rats of different ages, and the general method, a modification of the time-honored labyrinth. Instead of the usual form, however, I constructed a zinc tank, 2 feet, 1 inch square, and 6 inches deep, and covered it with coarse-mesh zinc netting, in the exact center of which a circular opening, fitted with a cylindrical shoot, serves as an entrance for the animals. At each of the four corners the cover, which is firmly clamped to the sides of the tank, has a small hinged door that can be opened at will, or made fast, likewise by means of clamps.

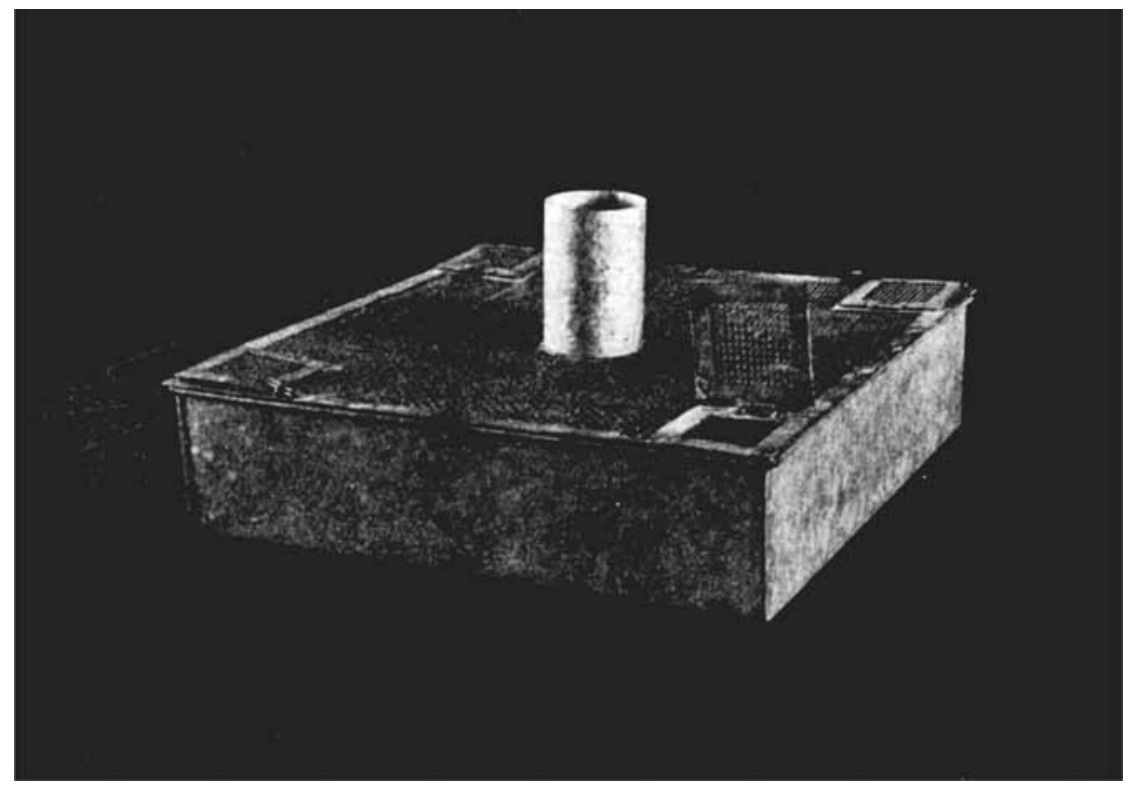

FIG. 1. Tank. Photograph by Miss Frances Dunbar. Dimensions 2 feet 1 inch square; depth, 6 inches; diameter of funnel, 4 inches; height of funnel, 6 inches; exits, 3 inches square. 
During the experiments, the tank was filled, sometimes with warm, sometimes cold water; salt was added on some occasions, whereas on others additional stimuli were administered while the animals were falling through the shoot or after they had emerged through the open door. As there are four openings, any one of which may be made the correct one, and as the contents of the tank may be varied in many ways, and the experiences on entering and emerging complicated as much as one desires, the tank is in a real sense, labyrinthine, although simple in construction.

\section{GENERAL RESULTS}

It is needless to say that an inexperienced animal suddenly thrust into a tank of water makes strenuous efforts to escape. Under the conditions of the experiments it is not surprising that a high degree of variability should attach to the several attempts of an animal forced to undergo the experience of the tank half a dozen times in succession. Nevertheless there is an underlying regularity, for the time taken to escape in 83 per cent of the cases is less at the last attempt than at the first, whereas in 16 percent it is greater, and in only 1 per cent unchanged.

Time records, while the most convenient form of registration, are nevertheless not the only ways in which the formation of a habit manifests itself. Very much to the point in this connection are tracings of the actual pathway pursued in escaping. Six such graphic representations are given in fig. 2, and show conclusively that the first turn of the path that led to the first escape occurs, often much abbreviated, and regardless of advantage, in nearly all of the succeeding trials.

In experiments into which so many complicating factors enter a regular and machine-like progress toward perfection cannot be expected, and its failure to appear is clearly shown in series $\mathrm{A}$ and B. Records $\mathrm{C}$ and $\mathrm{D}$, however, illustrate distinctly how the path followed was simplified until in the last trials it became to all intents and purposes a straight line. Hand in hand with this was a reduction in the amount of time taken to effect the escape. 
Two facts of considerable interest are to be read in these tracings. In series $B, C, D$, and $E$, the pathways are without exception dextral; in series $\mathrm{E}$, on the other hand, all the turns made are sinistral. A directive factor seems to be operative, but analysis shows that it may not be simple. A considerable number of tests was made with blindfolded animals, and with young whose eyes were not yet open. The results in general indicate that certain individuals have a natural disposition to turn to the right, rather than the left, in swimming, whereas in others the reverse tendency is equally marked. I have made no experiments to determine whether this tendency is due to differences in the semi-circular

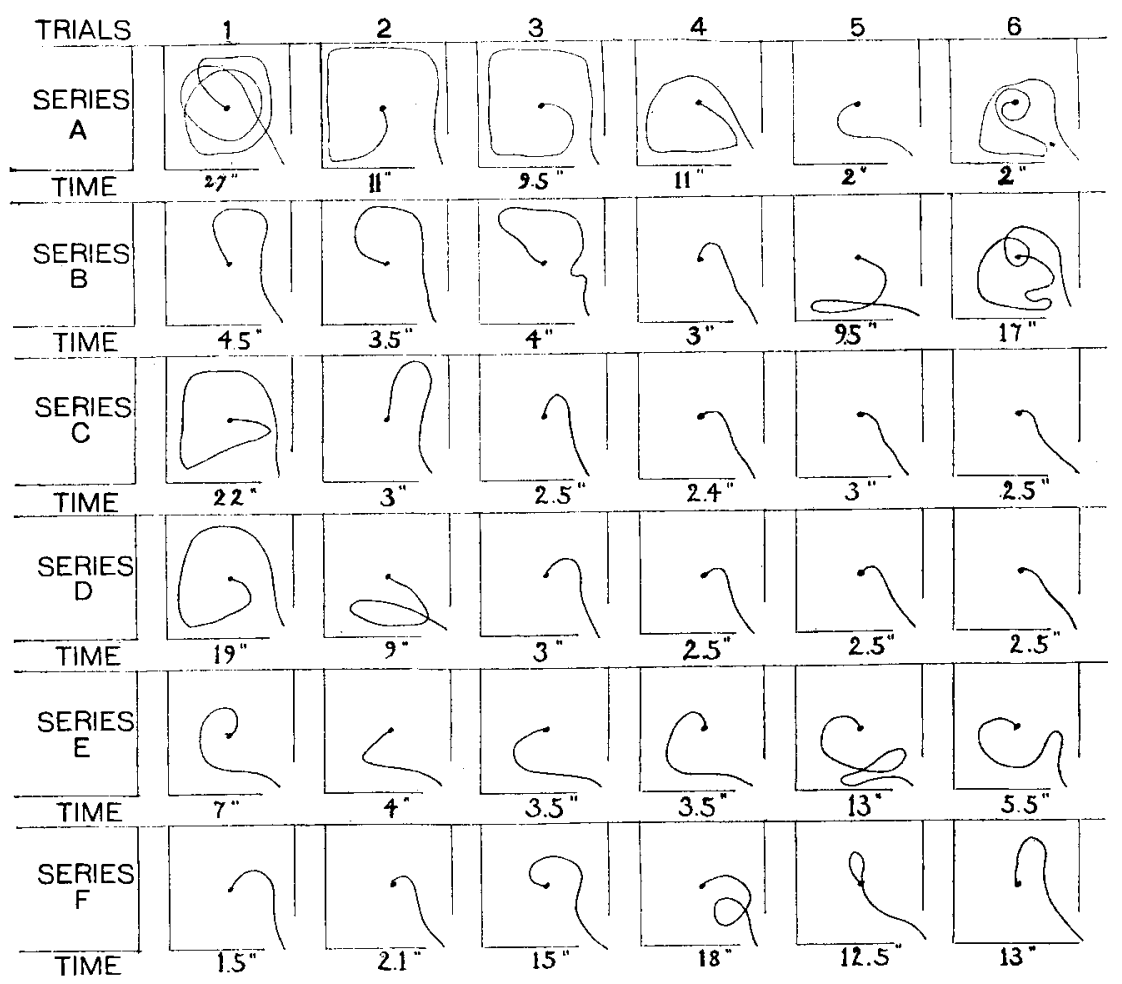

FIG. 2. Graphic representation of six sets of trials made by six individuals. The squares represent the tank, the incomplete corner, the open exit. Above the first series of records are figures indicating the number of each trial, whereas beneath the squares are the time records made in traversing the pathway indicated within each square. In every case the animal started from the central dot. 
canals, or to inequalities in the right and left swimming musculature, or the neuro-muscular coördinations, or to a combination of these possible factors. Any one of them, or any combination, except of course a compensatory one, might be responsible for the fact that some animals naturally turn to the right, others to the left.

The determination of the true basis of this behavior would be very difficult berause the repetition of the tests that bring it forth leads to the formation of a habit. That such becomes established, is, I think, sufficiently clear from the diagrams, as well as from the time records beneath them. Very interesting are series of which A is typical. In these, an animal, either because of its structure or its habit, turns consistently in one direction, in the present example, to the right. For some reason, exactly the reverse course was taken, with great success, at the fifth trial, and the sixth shows distinctly how this new departure complicated the course.

Series A illustrates a second fact, namely, that in many cases the pathway in succeeding trials becomes more complex, and the time consumed in escaping may increase. Nothing would be further from the truth than the conclusion that increase in either the complexity of the path or in the length of time, indicates progressive stupidity. The conditions of the experiments are such that a property analogous to cool-headedness in man, is at a premium. In many instances the animals became increasingly nervous, and lost their heads.

In problems whose solution can be effected, provided the animal has enough time and makes sufficient movements, this complication does not enter, but more than mere activity is necessary in a crisis. Animals which by luck or otherwise succeed early, behave much as they would in the face of "slow" problems; but animals that fail, or succeed only with difficulty, quickly become so handicapped by fear, and the useless activity characteristic of that state, that they fail more completely or succeed with much greater difficulty in later trials than they would in corresponding trials under more favorable conditions. While the experience of the tank brings out forcibly innate differences in the capacity to do the right thing quickly under stress, it is 
hardly adequate to measure real differences in the ability to learn. The individuals which are thrown out of commission, by the very nature of the problem itself, are simply out of the running; they are unable to compete, and their failure is no more to be ascribed to inferior intelligence than the failure of a blacksmith to win prizes at a swimming meet is to be ascribed to the superior strength of the other contestants.

Objectively, of course, the facts are that some animals fail, whereas others succeed. Success may come with progressive reduction in the complexity of the path, and in the time taken to traverse it, or with either of these elements separately; failure may result from the corresponding opposites. We can say with justice that the capacity to learn also expresses itself in one or more of these ways, but the obvious inference would not be the correct one. Should the chain of activities that we are interested in be inaugurated, our objective measurements would give us the information we want, but when some other chain is set up, the measurements show simply the extent to which the second disturbs the first chain. In other words, if the problems convert the animal into a non-learning mechanism, the movements which the individual performs throw no light on its learning capacity. What they do show is, that under the given circumstances, some animals improve, others do not, but the capacity of those that fail remains unknown. Even those that succeed do not divulge all. Strictly speaking, their capacity is shown to be not less than the records indicate, but actually it may be considerably more.

The animals that improve emphasize a practical question of some importance. There are plainly two ways of solving the tank problem; by increasing speed, and by decreasing the length of the pathway. Cases in which these two go hand in hand, or in which constancy of speed is offset by an abbreviation of the pathway, offer no difficulty; but what shall we say when increased complexity of the pathway is compensated for by beightened speed? If we limit ourselves entirely to the objective time measurements, such an individual may seem to improve or to hold its own; if, on the other hand, we study the pathway alone, the animal is clearly loosing in fitness. The sixth trial in series $\mathrm{A}$ is a concrete illustration. How shall such an individual be rated? 
As the objective records are at variance, it seems at first sight arbitrary to fix on either one or the other, and to say this is a measure of the truth.

Series C and D are from animals naturally well fitted to cope with the problem presented; natural fitness, however, varies, and some individuals inaugurate an overpowering set of altogether irrelevant, interfering movements. Such animals, practically, are not competing. Between these extremes most of the other individuals take their places, for their irrelevancies are not sufficient to destroy all chances of success, though marked enough to affect the general averages. The problem is to get out of the tank as quickly as possible, and is solved both by the animal that reduces the complexity of its path, either with or without an increase of speed, and by the animal that compensates inferiority in one direction by superiority in another. The latter might even win, but if we were offering prizes, justice would demand one for improvement in speed, the other for improvement in form. As form in the end makes for speed, not in individual cases, but on the average, the time records may be adopted officially as a practical, though not necessarily complete, measure of fitness.

\section{SPECIFIC RESULTS}

\section{ADULT RATS}

The first experiments were made with a tank differing slightly in size from the one described, and the animals. instead of being dropped into the water through a shoot that landed them in the exact center, were thrown in from one side, with a slight whirling movement. There was but one corner opening through which escape might be effected. The problem was thus essentially the same as the one described, and the differences in the records are mainly due to differences in the sizes of the two tanks, and to the way in which the animals were introduced. The whirling movement was adopted in order to insure that the effort to escape might not be begun in any except a chance direction. The results are tabulated below in self-explanatory form. 


\begin{tabular}{|c|c|c|c|c|c|c|c|c|}
\hline \multicolumn{3}{|c|}{ ANIMAL I. } & \multicolumn{3}{|c|}{ ANIMAIS II. } & \multicolumn{3}{|c|}{ ANIMAL HI. } \\
\hline Trials & Time & Intervals & Trials & Time & Intervals & Trials & Time & Intervals \\
\hline 1 & $19.0^{\prime \prime}$ & 0 & 1 & $14.0^{\prime \prime}$ & 0 & 1 & $6.0^{\prime \prime}$ & $1^{\prime} 30^{\prime \prime}$ \\
\hline 2 & $3.5^{\prime \prime}$ & 0 & 2 & $11.0^{\prime \prime}$ & 0 & 2 & $9.0^{\prime \prime}$ & $1^{\prime} 10^{\prime \prime}$ \\
\hline 3 & $2.0^{\prime \prime}$ & $1^{\prime}$ & 3 & $9.0^{\prime \prime}$ & $1^{\prime}$ & 3 & $8.4^{\prime \prime}$ & $1^{\prime} 30^{\prime \prime \prime}$ \\
\hline 4 & $5.0^{\prime \prime}$ & $15^{\prime}$ & $\dot{4}$ & $5.0^{\prime \prime}$ & 0 & 4 & $26.0^{\prime \prime}$ & $2^{\prime} 03^{\prime \prime}$ \\
\hline 5 & $3.5^{\prime \prime}$ & 0 & 5 & 2. $0^{\prime \prime}$ & $15^{\prime}$ & 5 & $1.4^{\prime \prime}$ & $2^{\prime} 00^{\prime \prime}$ \\
\hline \multirow[t]{7}{*}{6} & $2.5^{\prime \prime}$ & & 6 & $2.9^{\prime \prime}$ & 0 & 6 & 1. $0^{\prime \prime}$ & Hours \\
\hline & & & 7 & $17.0^{\prime \prime}$ & & 7 & $1.4^{\prime \prime}$ & $1^{\prime} 32^{\prime \prime}$ \\
\hline & & & & & & 8 & $1.2^{\prime \prime}$ & $1^{\prime} 20^{\prime \prime}$ \\
\hline & & & & & & 9 & $1.6^{\prime \prime}$ & $2^{\prime} 40^{\prime \prime}$ \\
\hline & & & & & & 10 & $2.4^{\prime \prime}$ & $0^{\prime} 40^{\prime \prime}$ \\
\hline & & & & & & 11 & $2.0^{\prime \prime}$ & $0^{\prime} 45^{\prime \prime}$ \\
\hline & & & & & & 12 & $1.0^{\prime \prime}$ & \\
\hline
\end{tabular}

Characterization, Animal 1 : At first many trial movements, then stopped investigating. In the end did not hurry out. Averages : first three trials, 8.16"; second three trials $3.66^{\prime \prime}$. Improvement, 55.1 per cent.

Characterization, Animal II: Accidental delay at second trial. Numerous extra movements in fourth. In seventh gave up trying to get out, hence this record is omitted in the averages. Averages : first three trials, 11.33"; second three trials, 3.33". Improvement, 70.8 per cent.

Characterization, Animal III: Slight delay in starti.g watch at eighth trial. Averages: first six trials, $4.73^{\prime \prime}$; second six trials, $1.60^{\prime \prime}$. Improvement, 66.3 per cent.

\begin{tabular}{c|r|c|c|c|c|c|c|c}
\hline \multicolumn{3}{c|}{ ANIMAL IV. } & \multicolumn{3}{c|}{ ANIMAL v. } & \multicolumn{3}{c}{ ANIMAL VI. } \\
\hline Trials & Time & Intervals & Trials & Time & Intervals & Trlals & Time & Intervals \\
\hline 1 & $57.4^{\prime \prime}$ & $30^{\prime \prime}$ & 1 & $55.2^{\prime \prime}$ & $30^{\prime \prime}$ & 1 & $13.1^{\prime \prime}$ & $30^{\prime \prime}$ \\
2 & $3.2^{\prime \prime}$ & $30^{\prime \prime}$ & 2 & $7.1^{\prime \prime}$ & $30^{\prime \prime}$ & 2 & $18.1^{\prime \prime}$ & $30^{\prime \prime}$ \\
3 & $8.2^{\prime \prime}$ & $30^{\prime \prime}$ & 3 & $5.1^{\prime \prime}$ & $30^{\prime \prime}$ & 3 & $4.3^{\prime \prime}$ & $30^{\prime \prime}$ \\
4 & $12.3^{\prime \prime}$ & $30^{\prime \prime}$ & 4 & $6.3^{\prime \prime}$ & $30^{\prime \prime}$ & 4 & $5.1^{\prime \prime}$ & $30^{\prime \prime}$ \\
5 & $8.2^{\prime \prime}$ & $30^{\prime \prime}$ & 5 & $5.2^{\prime \prime}$ & $30^{\prime \prime}$ & 5 & $5.2^{\prime \prime}$ & $30^{\prime \prime}$ \\
6 & $8.2^{\prime \prime}$ & $20^{\prime \prime}$ & 6 & $15.3^{\prime \prime}$ & $20^{\prime \prime}$ & 6 & $3.3^{\prime \prime}$ & $20^{\prime \prime}$ \\
7 & $9.3^{\prime \prime}$ & $30^{\prime \prime}$ & 7 & $3.3^{\prime \prime}$ & $30^{\prime \prime}$ & 7 & $12.2^{\prime \prime}$ & $30^{\prime \prime}$ \\
8 & $4.4^{\prime \prime}$ & $30^{\prime \prime}$ & 8 & $6.0^{\prime \prime}$ & $30^{\prime \prime}$ & 8 & $13.1^{\prime \prime}$ & $30^{\prime \prime}$ \\
9 & $4.3^{\prime \prime}$ & $30^{\prime \prime}$ & 9 & $12.2^{\prime \prime}$ & $30^{\prime \prime}$ & 9 & $22.3^{\prime \prime}$ & $30^{\prime \prime}$ \\
10 & $3.2^{\prime \prime}$ & $30^{\prime \prime}$ & 10 & $19.2^{\prime \prime}$ & $30^{\prime \prime}$ & 10 & $8.0^{\prime \prime}$ & $30^{\prime \prime}$ \\
11 & $3.1^{\prime \prime}$ & $30^{\prime \prime}$ & 11 & $4.0^{\prime \prime}$ & $30^{\prime \prime}$ & 11 & $31.4^{\prime \prime}$ & $30^{\prime \prime}$ \\
12 & $5.0^{\prime \prime}$ & & 12 & $4.0^{\prime \prime}$ & & 12 & $4.3^{\prime \prime}$ & \\
& & & & & & & & \\
\hline
\end{tabular}


Characterization, Animal IV : Animal quiet. Averages: first six trials, 16.25"; second six trials, 4.88." Improvement, 70 per cent.

Characterization, Animal V: Animal quiet. Averages: first six trials, 15.7"; second six trials, 8.11." Improvement, 48.4 per cent.

Characterization, Animal VI: Animal quiet in the first six trials, and apparently improving at a good rate. In the second set, however, it suddenly became "cranky" and did everything except the expected; it swam around aimlessly, or clawed the covering screen. Averages: first six trials, $8.18^{\prime \prime}$; second six trials, $15.20 "$. "Deterioration," 85.8 per cent. This record is of necessity omitted in the later calculations.

Naturally there is much unevenness in these records, and at times the irregularities seem to obscure the evidence that a habit was formed, or to show that the exact opposite was established. Nevertheless there is a fundamental harmony beneath the discrepancies, and this is not destroyed even when the record of animal VI is admitted. For obvious reasons, however, it would be unfair to allow this animal to figure in calculations that involve the group of animals as a whole. On similar grounds I have excluded the 7th trial of animal II, for on that particular occasion this individual also very clearly did not attempt to escape. If with these modifications the results be taken as they stand, we can construct the foilowing table for comparisons:

\begin{tabular}{|c|c|c|c|}
\hline & & $\begin{array}{l}\text { FIRST HALF RECORD } \\
\text { A verages } \\
\text { Seconds }\end{array}$ & $\begin{array}{c}\text { SECOND HALF RECORD } \\
\text { Averages } \\
\text { Seconds }\end{array}$ \\
\hline Animal & I. & 8.16 & .3 .66 \\
\hline Animal & II. & .11 .33 . & .3 .33 \\
\hline Animal & III. & $4.73 \ldots$ & $\ldots 1.60$ \\
\hline Animal & IV. & $.16 .25 \ldots$ & $\ldots 4.88$ \\
\hline Animal & V. & 15.70 . & .8 .11 \\
\hline
\end{tabular}

Aglance at this record shows that experience, even when limited to very brief periods of intense activity, has its effect, and in the adults composing this group brought about on the average an increase of 6.89 seconds in speed, or an improvement of 62.1 per 
cent. Considering the unfavorable conditions for the formation of a habit which these experiments present, the result is very marked.

\section{YOUNG RATS}

That this conclusion is not a mistaken one, is indicated by a similar treatment of the records of very young animals that underwent the experience of the tank. The individuals whose performances are tabulated in detail below were all from the same litter, and were aged three and a half weeks.

\begin{tabular}{c|c|c|c|c|c}
\hline \multicolumn{3}{c|}{} & \multicolumn{3}{c}{ ANIMAL B. } \\
\hline Trials & Time & Intervals & Trials & Time & Intervals \\
\hline 1 & $9.0^{\prime \prime}$ & $1^{\prime} 25^{\prime \prime}$ & 1 & $5.0^{\prime \prime}$ & $15^{\prime \prime}$ \\
2 & $4.0^{\prime \prime}$ & $44^{\prime \prime}$ & 2 & $13^{\prime \prime}$ & $37^{\prime \prime}$ \\
3 & $5.0^{\prime \prime}$ & $19^{\prime \prime}$ & 3 & $14^{\prime \prime}$ & $27^{\prime \prime}$ \\
4 & $2.5^{\prime \prime}$ & $43^{\prime \prime}$ & 4 & $10^{\prime \prime}$ & $25^{\prime \prime}$ \\
5 & $5.0^{\prime \prime}$ & $28^{\prime \prime}$ & 5 & $4.5^{\prime \prime}$ & $30^{\prime \prime}$ \\
6 & $2.0^{\prime \prime}$ & $45^{\prime \prime}$ & 6 & $5.0^{\prime \prime}$ & $31^{\prime \prime}$ \\
7 & $3.0^{\prime \prime}$ & $23^{\prime \prime}$ & 7 & $7.0^{\prime \prime}$ & $1^{\prime \prime} 2^{\prime \prime}$ \\
8 & $1.3^{\prime \prime}$ & $45^{\prime \prime}$ & 8 & $3.5^{\prime \prime}$ & $1^{\prime} 9^{\prime \prime}$ \\
9 & $1.5^{\prime \prime}$ & $1^{\prime \prime} 10^{\prime \prime}$ & 9 & $4.5^{\prime \prime}$ & $1^{\prime \prime} 8^{\prime \prime}$ \\
10 & $1.0^{\prime \prime}$ & $1^{\prime} 15^{\prime \prime}$ & 10 & $2.0^{\prime \prime}$ & $58^{\prime \prime}$ \\
11 & $2.0^{\prime \prime}$ & $56^{\prime \prime}$ & 11 & $5.5^{\prime \prime}$ & $32^{\prime \prime}$ \\
12 & $2.0^{\prime \prime}$ & & 12 & $6.0^{\prime \prime}$ & \\
& & & & &
\end{tabular}

Characterization, Animal $A$ : Animal between three and four weeks old; quick in its movements and not easily confused. Took a new route at the fifth trial, but at the sixth headed at once in the proper direction. Averages: first six trials, $4.58^{\prime \prime}$; second six trials, $1.8^{\prime \prime}$. Improvement, 60.7 per cent.

Characterization, Animal $B$ : Animal between three and four weeks old; quick but irregular and not to be counted on. In the twelfth trial ducked under just before emerging, and lost considerable time. Averages: first six trials, 8.56"; second six trials, $4.75^{\prime \prime}$. Improvement, 44.6 per cent.

Taking the figures as they stand, and comparing the average of the first half-record of each animal with the average of the second half-record, we get the following: 


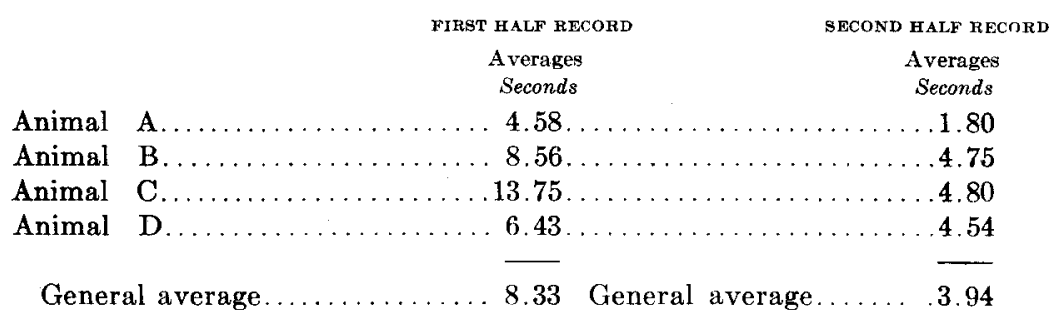

Here, too, is evidence that the behavior was modified by the "tank experience," but much more interesting is the fact that the changes undergone seem to harmonize very closely with the results secured by Watson ('03) under much more favorable conditions. The increase in the speed of the young animals was

\begin{tabular}{|c|c|c|c|c|c|}
\hline \multicolumn{3}{|c|}{ ANIMAL C. } & \multicolumn{3}{|c|}{ ANIMAL $\mathbf{D}$. } \\
\hline Trials & Time & Intervals & Trials & Time & Intervals \\
\hline 1 & $8.5^{\prime \prime}$ & $42^{\prime \prime}$ & 1 & $10.5^{\prime \prime}$ & $24^{\prime \prime}$ \\
\hline 2 & $33.0^{\prime \prime}$ & $22^{\prime \prime}$ & 2 & $8.5^{\prime \prime}$ & $35^{\prime \prime}$ \\
\hline 3 & $19.0^{\prime \prime}$ & $20^{\prime \prime}$ & 3 & $5.8^{\prime \prime}$ & $1^{\prime} 10^{\prime \prime}$ \\
\hline 4 & $9.0^{\prime \prime}$ & $34^{\prime \prime}$ & 4 & $5.8^{\prime \prime}$ & $40^{\prime \prime}$ \\
\hline 5 & $9.0^{\prime \prime}$ & $36^{\prime \prime}$ & 5 & $6.0^{\prime \prime}$ & $47^{\prime \prime}$ \\
\hline 6 & $4.0^{\prime \prime}$ & $53^{\prime \prime}$ & 6 & $2.0^{\prime \prime}$ & $56^{\prime \prime}$ \\
\hline 7 & $3.0^{\prime \prime}$ & $1^{\prime}$ & 7 & $7.0^{\prime \prime}$ & $40^{\prime \prime}$ \\
\hline 8 & $3.0^{\prime \prime}$ & $1^{\prime} 4^{\prime \prime}$ & 8 & $3.0^{\prime \prime}$ & $53^{\prime \prime}$ \\
\hline 9 & $3.0^{\prime \prime}$ & $43^{\prime \prime}$ & 9 & $3.3^{\prime \prime}$ & $1^{\prime} 10^{\prime \prime}$ \\
\hline 10 & $2.8^{\prime \prime}$ & $1^{\prime} 7^{\prime \prime}$ & 10 & $6.0^{\prime \prime}$ & $58^{\prime \prime}$ \\
\hline 11 & $4.0^{\prime \prime}$ & $1^{\prime} 28^{\prime \prime}$ & 11 & $4.3^{\prime \prime}$ & $42^{\prime \prime}$ \\
\hline 12 & $13 . v^{\prime \prime}$ & & 12 & $3.5^{\prime \prime}$ & \\
\hline
\end{tabular}

Characterization, Animal $C$ : Animal between three and four weeks old; very quick and nervous. In first trial explored all corners, became panic-stricken in the second, better in the third, but during the fourth lost much time clawing the wire screen. In the last half of the series the animal seemed to have found itself, and exhibited no semblance of fear. The length of the twelf th trial is due to having overshot the opening. Averages: first six trials, 13.75"; second six trials, 4.8". Improvement, 64.4 per cent.

Characterization, Animal D: Animal between three and four weeks old. Relatively slow and indifferent. Averages: first six trials, $6.43^{\prime \prime}$; second six trials, 4.57". Improvement, 29.9 per cent. 
on the average 4.39 seconds, for the adults 6.89 seconds; the former represents an increase of 53 per cent in efficiency, whereas the adults improved 62.1 per cent.

\section{DURATION OF TIIE HABIT}

That a habit formed under stress during brief periods of intense activity, may endure from fifteen minutes to several hours, the records already given show plainly. Special tests were made, however, to determine, if possible, whether any traces of the heightened efficiency might be found after several days. For this purpose, animals $\mathrm{A}, \mathrm{B}$, and $\mathrm{C}$, of the preceding group of young were used, and adults $\mathrm{A}, \mathrm{B}, \mathrm{C}, \mathrm{D}, \mathrm{E}$, and $\mathrm{F}$, upon whose records fig. 2 is based. In the present connection I shall distinguish the three young animals by small letters, the six adults by means of capitals.

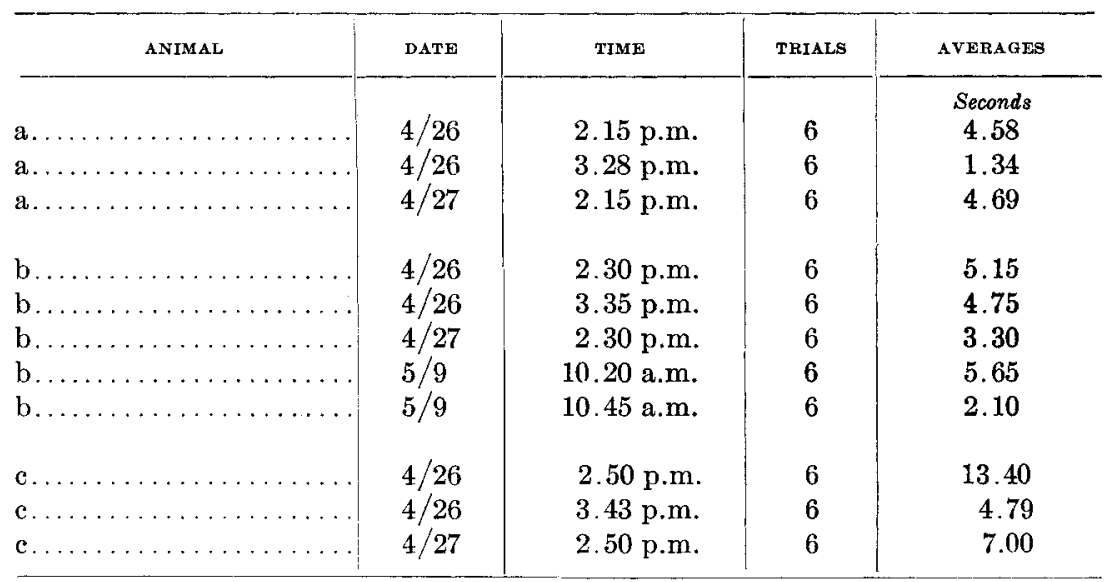

The adults A, B, C, D, E, and F, whose records on January 15 th, 20 th, $22 \mathrm{~d}$, and 28 th follow, were all used prior to December 11 th of the year before, but unfortunately the earlier experiments were not performed under exactly the same conditions as those made in January, and a comparison of records separated in time by more than a month cannot be made. The results of the series separated in time by five days, by two, and again by six, can, however, be safely compared. 


\begin{tabular}{|c|c|c|c|c|}
\hline \multirow{2}{*}{ ANIMAL } & DATE & DATE & DATE & DATE \\
\hline & Jan. 15 & $\operatorname{Jan} .20$ & Jan. 22 & Jan. 28 \\
\hline & Seconds & Seconds & Seconds & Seconds \\
\hline A. & 10.40 & 1.66 & 1.91 & 2.08 \\
\hline B. & 6.90 & 10.25 & 5.83 & 6.00 \\
\hline C. & 5.90 & 9.08 & 13.75 & 10.50 \\
\hline D. & 6.41 & 5.66 & 6.08 & 6.08 \\
\hline E. & 6.08 & 32.82 & 11.41 & 9.75 \\
\hline F... & 15.75 & 19.00 & 16.00 & 10.16 \\
\hline General average... & 8.58 & 13.08 & 9.16 & 7.33 \\
\hline
\end{tabular}

The results from the young animals are not especially conclusive. Taking the records as they stand, however, it may be said that two out of the three seemed to show the effects of their experiences twenty-four hours afterward, and one of the animals, after twelve days, very quickly recovered and in the end actually bettered its previous best record. It is to be expected, of course, that individuals vary greatly in the length of time which their habits, whether formed slowly or rapidly, endure; and furthermore, there is no way in which one can be reasonably certain, except by the method of multiple instances, whether, in the long run, animals without previous experience might not, on the whole, make as good records as those made by experienced individuals. As far as the group as a whole is concerned, it does not seem to bear markedly one way or the other on this particular question, although it does show that the final records of animals $b$ and $c$ were better than their initial ones.

Considering the adults, not as individuals, but as a group, and comparing the averages of the four series, we get the results as tabulated. Individual differences notwithstanding, we may say that, on the whole, the second set of trials, five days after the first, was distinctly slower; the third, two days after the second, not as slow as the preceding, whereas the fourth, six days after the third, was the best of all. Of course, these statements have no bearing on specific cases. The record as given is sufficiently detailed to show how the relative fixity in one individual is balanced, and even discounted by the relative instability of another, or vice versa. 


\section{INTRODUCTION OF ADDITIONAL STIMULI}

The "tank experience" may be complicated by the introduction of additional factors, which, classified by their effects, may be called retarding and accelerating stimuli. Marked accelerations were produced by allowing the animals before reaching the water in the tank, to fall through a paper bag filled with water considerably warmer; also if, during their fall through the cylinder, the animals received an electric shock, the speed was increased. On the other hand, the addition of salt in small quantities to the water in the tank had, on the average, a depressing effect. The most marked, as well as constant effects, however, were gotten by the system of desired rewards. Animals that had been without food for twenty-four hours, were dropped into disagreeably cold water, and immediately on escaping, were wrapped in warm towels and given a nibble of cheese. All these factors helped to make escape from the tank better worth while than it had been in any of the preceding experiments. The results, based on two full-sized adults, and on eight young, less than a year old, are tabulated below. As heretofore, the adults are labelled with capitals, the young with small letters.

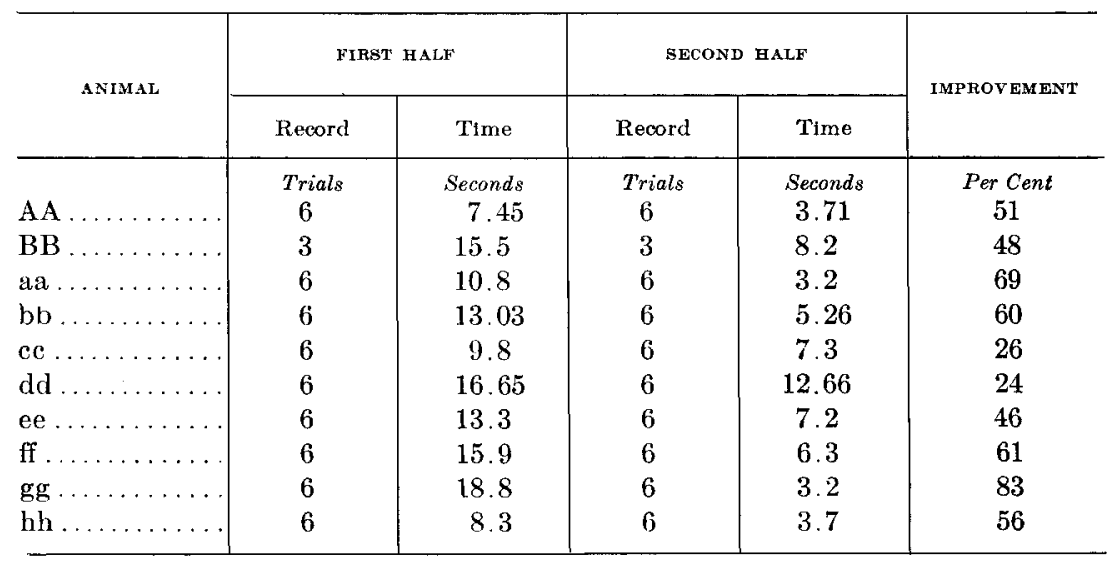

Not only are the adults too few, but the number of trials made is too small to allow of satisfactory comparison with the earlier records made under simpler conditions. Neither AA nor BB 
improved as much as the adults in former experiments, but this may have been because they were unusually slow. If a conclusion may be hazarded, it is that the additional stimuli had no effect or perhaps a slightly depressing one, though this is uncertain.

The young, on the other hand, improved on the average 62.5 per cent, as compared with an earlier record of 53 per cent. Animals cc and dd have been eliminated from these calculations on the ground of over-excitedness. The results might have been expected. There was an unmistakable effect on the young, and in two cases the additional discomforts and rewards produced so much activity, that these particular records were vitiated by it.

\section{THE SENSES AND THE HABIT}

The relation between the senses and the acquisition of habits in the white rat has been so thoroughly worked over by Watson ('07) that I have performed only a few experiments, the results of which I shall present for two reasons, first because they are corroborative, in spite of the differences in method; secondly, because they show that the various senses can be eliminated without resorting to the extirpation, or destruction of the sense organs. Under the conditions of the experiments, hearing, smell, sight, and touch, either singly or in any combination, may conceivably furnish the sensual basis on which the habit rests.

\section{HEARING}

As the associations were formed while one of the four exits was open, it may have been that the movements of the animals were influenced by the differences in sound intensity or quality due to the unblocked passage. Such differences, if they exist, must be very small, for the closed openings are blocked simply by wire netting, but as rats are known to perceive minute sound differences, the point was well worth testing.

Associations were established in the usual way, after which 
the exit to which the animal had been trained, was closed and one or several of the others were opened. In every case the individuals continued to go to the exit from which they had previously escaped. Of course this test could not be continued indefinitely, as failure to escape from the tank, resulted in new exploratory movements that in the end led the animals to one of the other openings. Frequent visits to the old corner are characteristic of these secondary trials.

In another experiment, the association was established amid general noise, so great just above the center of the tank, that probably there were no differences at any of the corners. When the animals, after a brief rest, were placed again in the tank, they were allowed to make their second series of trials in absolute silence. In all cases they swam to the right place with no more variation in time or in the complexity of the pathway than is found under ordinary conditions.

A third test was made by allowing the association to establish itself while a noise was made at one of the other opened escapes. These noises, purposely not loud enough to frighten the animals, but certainly marked enough to be audible, seemed to have no effect whatever.

SMELL

To determine the part played by the sense of smell, the exit left open was thoroughly perfumed with cheese. After the association was established, the tank was turned in such a way that the perfumed opening was diagonally opposite its original position, whereas another exit, unperfumed, occupied geographically the place previously held by the escape to which the animal had been trained. Variations of this plan, such as holding a piece of cheese, first in one corner, then in another, were also tried, but in each case the animals swam in the direction that led to the earlier escapes. So far as these tests of the importance of smell are concerned, they give only negative results. 
The experiments on sight bear simply on such rays as we ourselves are able to perceive, and were performed in a carefully constructed and thoroughly efficient photographic dark room. From the subjective standpoint, the animals were allowed to swim in the dark, but whether what we call dark is in reality dark to a rat, is another question.

Two sets of animals were used, two adults, and two young ones less than a year old. Each animal was given four sets of six trials. The averages follow:

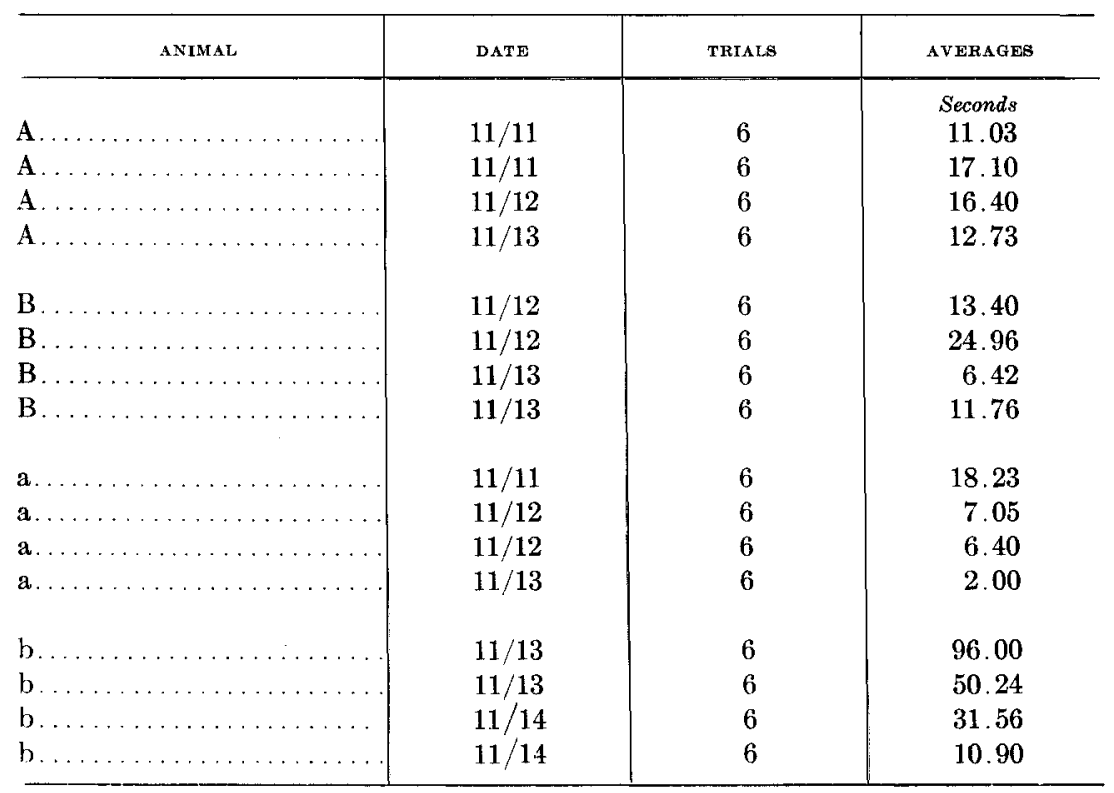

If the first two series of $\mathrm{A}$ are compared with the last two, it will be found that this animal remained practically constant in speed; if a similar comparison be made for $\mathrm{B}$, we find that this individual increased its speed on the average by $9.28^{\prime \prime}$; whereas the records of $a$ and $b$ show increases in efficiency in each of the last three sets. Undoubtedly, then, the tank problem can 
be solved in the dark, and the solution, may with repetition, become a habit, but the evidence does not show that the sense of sight plays no part under other circumstances. Watson's negative evidence on this point seems very good, but the maze problem and the tank problem differ so much, that what is true in the solution of the one, is not of necessity true in the solution of the other.

\section{TOUCH}

Touch in the ordinary sense, is practically eliminated by the nature of the problem. The actual solution takes place in a medium in which the animals float. There are no solid bodies to be touched; no differences in homogenity in any direction, that might guide the individuals to the correct opening. The same thing applies to the temperature sense. It is possible, however, that touch and temperature, singly or together, affect the result, but if they do, it is not in the usual way, but as the initiating stimuli of other activities.

\section{THE KINASTHETIC CHAIN}

With hearing, smell, sight and touch, either eliminated, or shown to be not essential, the question of how the habit becomes established, naturally arises, Watson ('07) and others have presented a large body of evidence suggesting that the kinæsthetic sense may be the controlling factor in the behavior of the white rat. My own experiments seem to bear similar interpretation, but if the facts corroborated by the tank method are due to a kinæsthetic sense, it follows that this needs investigation.

Granted that a relation exists between the objective phenomena which we call a habit, and the inferred basal kinæsthesia, the inference that the relation is definite, seems just; for the habit itself is definite, and capable not only of exact measurement, but also of modification. It follows that in the emergence of a habit, the internal basis also is modified, for the habit itself is modified behavior. In other words, kinæsthesia is easier to understand if 
thought of as a sequence of states which will be repeated, provided the physiological state of the animal remains favorable, whenever the stimuli that started it in the first place recur.

It is here that any sensations associated with the beginning of a solution may come into play. Unfortunately, I have no results to offer on this subject at present, but the standpoint itself may not be without value. If kinæsthesia is indeed a special element in the sum total of internal conditions, is in fact a chain, based on the physiological, and expressed objectively in the habit, the answer to a difficult problem may be a little easier to find than heretofore.

\section{SUMMARY AND CONCLUSIONS}

- My purposes in presenting these results have been to show the adequacy of the tank as an instrument for studying animal behavior; to show that our usual methods leave out of consideration a large range of interesting activities; and finally to demonstrate that behavior, limited to brief periods of very intense exertion under stress, may lead to the formation of habits.

Incidentally, the results seem to corroborate, as far as they go, some of the conclusions set forth in Watson's splendid work, and wherever at variance, are so probably from the differences between the problem of the maze, and the problem of the tank. In certain ways, the latter seems well suited for studying the "direction sense" or whatever it is that in the absence of sight, hearing, smell, and touch, enables the animals, not only to solve the problem, but to improve in efficiency. If kinæsthesia plays an important role, if indeed it is by this means that the animals sense direction, and if furthermore, it is a sequence of states, dependent on the physiological condition of the animal, and on certain initiating stimuli, then by variations in the last two categories, one should get changes in kinæsthesia, which in turn would be registered by corresponding differences in the objective habit. 


\section{BIBLIOGRAPHY}

Warson, JoHn B. Animal Education. The University of Chicago Contributions 1903 to Philosophy, vol. 4, no. 2.

Watson, John B. Kinæsthetic and Organic Sensations, etc. Psychological 1907 Review, Monograph Supplements, vol. 8.

Zoölogical Laboratory, University of Michigan.

January 13th, 1910. 